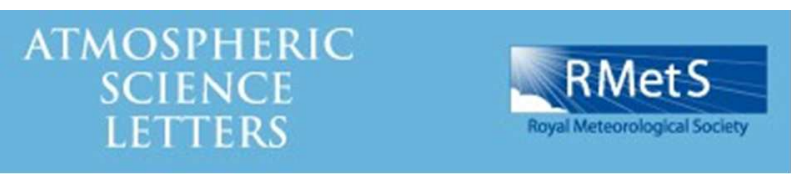

\title{
The North American winter 'dipole' and extremes activity: A CMIP5 assessment
}

\begin{tabular}{|r|l|}
\hline Journal: & Atmospheric Science Letters \\
\hline Manuscript ID: & ASL-14-132.R2 \\
\hline Wiley - Manuscript type: & Research Article \\
\hline Complete List of Authors: & $\begin{array}{l}\text { Wang, Shih-Yu; Utah State University, Plants, Soils, and Climate } \\
\text { Huang, Wan-Ru; NTNU, } \\
\text { YOON, JIN-HO; PNNL, }\end{array}$ \\
\hline Keywords: & polar vortex, California drought, dipole, CMIP5, ENSO precursor \\
\hline \multicolumn{2}{|l}{} \\
\hline
\end{tabular}




\title{
The North American winter 'dipole' and extremes activity: A CMIP5 assessment
}

\author{
S.-Y. Simon Wang, ${ }^{12}$ Wan-Ru Huang, ${ }^{3}$ and Jin-Ho Yoon ${ }^{4}$
}

1. Utah Climate Center, Utah State University, Logan, UT

2. Department of Plants, Soils and Climate, Utah State University, Logan, UT

3. Department of Earth Sciences, National Normal University, Taipei, Taiwan

4. Pacific Northwest National Laboratory, Richland, WA

\begin{abstract}
The 2013-2014 winter in North America brought intense drought in the West and severe cold in the East. The circulation anomalies were characterized as a dipole: an amplified upper-level ridge over the West Coast and a deepened trough over the central-eastern U.S. A previous study using a single model has linked the dipole to the El Niño precursor and found that this link has strengthened in recent years. Here, 17 models from the Coupled Model Intercomparison Project Phase 5 are utilized to examine the dipole activity. Most models capture the dipole and its association with El Niño precursor and project this association to strengthen.
\end{abstract}

\section{Introduction}

The winter season of 2013-2014 in North America has been one of the most extreme: an intense drought in the West (California declared 100\% in severe drought in April) and extremely low temperatures across the central and eastern U.S. (resetting at least 49 daily record lows in the U.S.; USA Today 1/7/2014). Coined by media as "polar vortex", the consecutive cold spells in early 2014 stalled the U.S. economy costing about \$5 billions (The Guardian, 1/9/2014).

Meanwhile, the exceptional drought in California continues to generate new challenges to the society in addition to the drought's apparent impact on agriculture and water resources. 
The meteorological cause of the 2013-14 California drought and the severe cold in the East was a persistent and high-amplitude upper-level ridge developed over the West Coast in November through January. Coupled with the deepened trough in the East, such upper-level circulation setting was referred to as a dipole (Fig. 1a) and its exceptionally large amplitude was linked to a teleconnection pattern associated with the developing phase of El Niño (i.e. a precursor over the Western Pacific Ocean) [Wang et al., 2014]. During winter of 2013-2014, SST was warm in the western tropical Pacific yet abnormally cold along the Asian coasts, forming a substantial SST contrast; this was accompanied by cyclonic flows and warmer water near Papua New Guinea [Wang et al., 2013a], triggering the teleconnection across the Pacific Ocean. Wang et al. [2014] showed that the Rossby wave energy emerged from the far western Pacific towards the central North Pacific since as early as summer 2013, and the wave activity flux amplified the 2013-2014 winter ridge over western North America.

The aforementioned SST and circulation anomalies are part of an emerging El Niño precursor [Larson and Kirtman, 2013; Wang et al., 2012; Wang et al., 2013a]. Meanwhile, the mechanisms to initiate or to maintain the "polar vortex" are under active debate: (a) the sea surface temperature (SST) over the western Pacific [Palmer, 2014] and (b) the Arctic sea ice reduction and associated increase in surface heat fluxes [Kim et al., 2014] have both been proposed as the potential causes. Recent studies [Kintisch, 2014; Palmer, 2014] have pointed out the important role of tropical forcing sources on the amplification of jet streams; this view is different from others based on polar warming and reduced meridional thermal gradient of the jet [Francis and Vavrus, 2012; Screen and Simmonds, 2013; Serreze and Francis, 2006] and requires further examination.

Based upon the Community Earth System Model version 1 (CESM1) [Hurrell et al., 2013], Wang et al. [2014] found that increased anthropogenic greenhouse gases (GHG) played 
an important role in intensifying the dipole through warming in the western Pacific and associated enhancement in the teleconnection towards North America. This finding was derived from only a single model, the CESM1. Therefore, it is prudent to examine simulations by multiple models for the dipole and its behavior change. In this study, we extended the analysis from Wang et al. [2014] by using simulations generated by multiple climate models from the Coupled Model Intercomparison Project Phase 5 (CMIP5) archive [Taylor et al., 2011].

\section{Data}

We analyzed 17 models from CMIP5's Historical single-forcing experiments driven by (1) all historical forcings (ALL), (2) only natural forcing including solar and volcano (NAT), and (3) only greenhouse gas forcing (GHG). Each experiment produced multiple members initialized from long-stable preindustrial (1850) control run up to 2005. Table 1 provides the full name, institute, ensemble size, and spatial resolution of these 17 models and that of CESM1 used by Wang et al. (2014). Future period were simulated with the Representative Concentration Pathways (RCP) 4.5 and 8.5 scenarios projecting the increases of radiative forcings caused by anthropogenic climate forcings. All model outputs were re-gridded to $2.5^{\circ}$ long. $\mathrm{x} 2.5^{\circ}$ lat. resolution before averaging. For observational data we utilized the NCEP/NCAR Reanalysis from 1948 to present [Kalnay et al., 1996], and global SST from the buoy-based extended data version 2 [Kaplan et al., 1998].

\section{Results}

a. Dipole formation

Wang et al. [2014] argued that the formation of the dipole during November 2013January 2014 (NDJ), shown in Fig. 1a, were attributable to (1) teleconnection emanating from 
the western Pacific and (2) increased anthropogenic GHG that has warmed the western Pacific. The first link is illustrated in Fig. 1b showing the NDJ 250-hPa geopotential height anomalies (Z250) regressed with the precursor of El Niño-Southern Oscillation (ENSO) represented by the Niño3.4 index shifted by one year, denoted as Niño3.4 (Y+1) (figure obtained from Wang et al. [2014]). The resemblance between Figs. 1a (2013-14 case) and 1b (regression pattern) suggests a close connection between the dipole and teleconnection of the ENSO precursor, and similar resemblance is also evident between the SST anomalies and regression (right panels). Wang et al. [2014] showed the Rossby wave energy propagation from the western Pacific and found that the CESM1 replicated such a connection.

Following Fig. 1b, the CMIP5 ensembles of Z250 and SST were regressed upon Niño3.4 $(\mathrm{Y}+1)$ for the ALL, GHG, and NAT forcing runs (Figs. 1c-e) for the period of 1960-2005; here the ensemble members were equally weighted. In terms of Z250, the ALL-forcing runs depicted the dipole reasonably well, and in the GHG-forcing runs the dipole is apparently more robust than the other two runs (spatial correlations confirmed so; not shown). In NAT (Fig. 1e), the dipole is not only weaker but also displaced, having shifted westward away from western North America. Moreover, the wave train in the Asia-western Pacific region is noticeably stronger in GHG than others. On the other hand, the regressed SST pattern (right panels in Figs. 1c-e) does not reveal as much a difference as Z250; in fact the tropical SST distributions are similar in all three runs. The little difference in the SST pattern raises a question concerning what forcing source produced the distinctly different Z250 patterns. To examine, Figs. 2a-c show the precipitation patterns over the ocean regressed with Niño3.4 $(\mathrm{Y}+1)$. The GHG-forced precipitation anomalies appear stronger than the ALL-forcing runs and are noticeably stronger than the NAT-forcing runs, despite the similar precipitation distributions among the three runs. Thus, even though the magnitude of SST anomalies does not change, the mean-state changes in 
SST and air temperature in response to GHG warming would amplify the precipitation responses due to increased evaporation and moisture content in the atmosphere [Collins et al., 2010; Stevenson et al., 2012]. Such a process would enhance the latent/diabatic heating anomalies and subsequently amplify the atmospheric teleconnection and stationary waves in the mid-latitudes [Palmer, 2014; Wang et al., 2014]. The multi-model simulations clearly support the CESM1 results in Wang et al. [2014] that increased GHG strengthens the teleconnection associated with the ENSO precursor.

Model biases do exist however: When compared with the observation (Fig. 1b), CMIP5 ensembles produced the cold tongue that is too strong and extends too far west, pushing the warm SST to be too close to the Philippines, while the tropical Atlantic appears to be too cold. (To compensate for the skewed 'cold tongue' in the CESM1, Wang et al. [2014] used the Niño-4 are to represent the ENSO variability, but here we will adopt the more commonly used Niño-3.4 area.) The signal of La Niña seems apparent in Fig. 1b; however, cooler water in the tropical Pacific appears stronger off the equator and this feature defies the typical cold tongue centered along the equator. Noteworthy is the significant correlation in the Indian Ocean in Fig. 1b, which suggests a possible role of the Indian Ocean SST in affecting the North American circulation. This aspect was explored with a focus on the Pacific-North America (PNA) teleconnection [Barsugli and Sardeshmukh, 2002; Farrara et al., 2000]. Earlier studies [Annamalai et al., 2007; Kumar and Hoerling, 1998; Spencer et al., 2004] also suggested an impact of the Indian Ocean SST anomalies on the North American climate, though those studies tended to focus on the extreme ENSO phases and the associated PNA pattern, which is not necessarily linked to the dipole.

\section{b. Dipole amplification}


By examining the difference in the precipitation responses between the GHG and the NAT runs, we identified two areas as a likely teleconnection source: one in the western tropical Pacific and the other in the equatorial Atlantic (outlined in Fig. 2b). These two tropical areas represent, approximately, the largest increases in precipitation (and subsequent latent heating) under increased GHG forcing. We then assessed the influence of these heating sources on the atmospheric circulation through the use of a linear barotropic model [Branstator, 1983; 1985]. To force the model, we applied vorticity forcing with a prescribed value of $2 \times 10^{-5} \mathrm{~s}^{-1}$, first onto the western Pacific area (indicated as a blue-filled box in Fig. 2d) and second, onto the equatorial Atlantic area (Fig. 2e); this was to depict the difference in the precipitation/heating response between Figs. 1d and 1e. For the model basic state we used the observed NDJ-mean streamfunction at $500 \mathrm{hPa}$ for the assumption of a barotropic atmosphere. The steady solutions of the streamfunction in response to the vorticity sources, both individually and collectively, are shown in Figs. 2d-f.

The western Pacific source produced a stationary wave response manifest as a transPacific wave train (Fig. 2d), forming a ridge to the west and a trough to the east of North America, resembling the dipole. The equatorial Atlantic forcing perturbed a wave response towards Europe and from there, generated a weak wave train across Asia and the North Pacific Ocean (Fig. 2e). The combined forcings (Fig. 2f) generated a stationary wave pattern very similar to that associated with those associated with the El Niño precursor (Fig. 1b) and the 2013-2014 anomalies (Fig. 1a). This result suggests an amplification of teleconnection given increased latent heating at the suggested regions, primarily the tropical western Pacific. Despite the crudeness of this simple diagnostic model, as it lacks moist processes, mid-latitude forcing, land and air-sea feedbacks and its response can be sensitive to the mean state, the marked similarity between the simulated and observed stationary waves did suggest that enhanced 
tropical precipitation anomalies in the "right spot" can strengthen the North American dipole, without the influence of a mature-phase ENSO event.

The diagnostics presented so far have been focused on the historical period. To assess the extent to which the dipole activity may change, we examined the CMIP5 projections under the RCP 4.5 and 8.5 scenarios. We first defined the dipole index by subtracting Z250 between the ridge center and the trough center indicated by the pair of crosses in Fig. $1 \mathrm{a}\left(144^{\circ} \mathrm{W}, 51^{\circ} \mathrm{N}\right)$, following Wang et al. [2014], and then normalized the index (between -2 and 2) for each member of each model by its standard deviation. Next, we computed the moving variance of the dipole index over a 30-year window; the value was plotted at the $30^{\text {th }}$ year. As shown in Fig. 3 , the moving variance of the GHG-forcing runs depicts a substantial increase by $18 \%$ after 1970 . The NAT-forcing runs indicate more or less a non-change despite the apparent multi-decadal variability. This contrast between GHG and NAT supports the CESM1-based analysis of Wang et al. [2014] that increased GHG can amplify the North American dipole. For the $21^{\text {st }}$ century, both RCP runs indicated an initial increase in the moving variances up to 2050, while RCP8.5 produced a continual increase after 2080; this projection indicates that the North American dipole activity will continue to amplify. However, it is worthy noting that depiction of the dipole from each model can be complicated because each model/member produces its own dominant 'modes' of the stationary wave variability. Thus, the dipole index as utilized here may contain other climate variability as well and associated changes.

\section{c. Dipole projection}

Based on the CESM1 simulations, Wang et al. [2013a] showed that increased GHG forcing has strengthened a particular type of ENSO precursor since the 1970s; this finding could provide an explanation to the association between the changing ENSO precursor and the dipole. 
To examine further, the sliding correlations between the dipole index and Niño3.4 $(\mathrm{Y}+1)$ were computed over a 30-year running window. As shown in Fig. 4a, each color line represents the ensemble of one model (note: CESM1 was not included here for the consideration of 'leave one out' validation). In the GHG-forcing runs, the correlations show an apparent increase, which supports the CESM1 results [Wang et al., 2014], though the ensemble mean (black thick line) does not exceed the $95 \%$ confidence level. By comparison, the NAT ensemble does not reveal any discernable change in the correlations.

The large model spread in the sliding correlations raises a concern regarding the robustness of our interpretation. This large inter-model spread can be caused by differences in simulating ENSO cycle, the ENSO precursor patterns, and related teleconnection patterns by each model. Thus, we further evaluated the depiction of the ENSO precursor. Fig. $4 \mathrm{~b}$ shows the spatial correlation coefficients $(\rho)$ between composite SST anomalies over the Pacific Ocean $\left(110^{\circ} \mathrm{E}-110^{\circ} \mathrm{W}, 45^{\circ} \mathrm{S}-45^{\circ} \mathrm{N}\right)$ from the simulation and observation, based on Niño3.4 $(\mathrm{Y}+1)$ exceeding $0.5^{\circ} \mathrm{C}$ during the NDJ seasons of $1960-2005$. This $\rho$ indicates 'model skill' on the ENSO precursor. Apparently, the CESM1 exhibited the highest skill, followed by nine models with $\rho$ greater than 0.45 . Eight other models showed $\rho$ less than 0.3 or below zero. Thus, the former nine models were grouped as the 'good-skill' models and these are indicated by solid color lines in Fig. 4a. When averaging only good-skill models, the mean correlation (red thick line) in the GHG-forcing runs became significant after 1990, but not in NAT; this reinforces the conclusion that increased GHG enhances the dipole's association with the ENSO precursor.

For the $21^{\text {st }}$ century, the RCP8.5 runs produced increased correlations up to 2070 before leveling off, while the RCP4.5 runs simulated a continuous increase towards the end of the century. The good-skill models exhibited a more robust increase than the all-model ensembles even though the correlations in the earlier part of $21^{\text {st }}$ century are lower than the all-model 
ensemble. In RCP8.5, the level off of the correlations around year 2070 may indicate a new equilibrium, since it coincides with the level after 2090 in the RCP4.5 runs. Though no RCP runs generated significant correlations in the ensemble means, the twofold increase in the sliding correlations is considered significant and suggestive of the GHG effect on ENSO precursor.

\section{Conclusions}

The abnormal winter climate in North America during 2013-2014 has led to an uncommon combination of extreme events: record drought and heat in the West accompanied by record cold in the central and eastern U.S. This climate anomaly started in the early winter of 2013-2014 when the upper-level circulation created a blocking ridge over the Gulf of Alaska, which deepened the trough downwind forming a dipole. The wavelength of this dipole is rather large (at zonal wave numbers 1-2 scale), surpassing the common short-wave (zonal wave numbers 4-6) patterns accompanying heat waves and stormy weather [Chang and Wallace, 1987; Screen and Simmonds, 2014; Teng et al., 2013; Wang et al., 2013b]. The long-wave feature of the dipole suggests a closer link with SST teleconnection from the tropical Pacific rather than with a higher-latitude forcing [Wallace and Gutzler, 1981]. Seventeen CMIP5 models were analyzed to test this connection and its association with increased GHG.

In general, the CMIP5 models can simulate the dipole and its association with the ENSO precursor reasonably, and the historical and the RCP simulations indicated that both the dipole and its association with the ENSO precursor would strengthen with increased GHG loading. These results support the CESM1 studies of both Wang et al. [2014] and Wang et al. [2013a] on the dipole and the changing ENSO precursor, although in the CMIP5 models the correlations of the GHG-forcing runs between the dipole index and the ENSO precursor did not pass the $95 \%$ confidence level. Nevertheless, the CMIP5 projections did indicate a marked increase in the 
association between the dipole and the ENSO precursor and portrayed a more rapid increase in the higher-concentration scenario (RCP8.5). It is also important to note that the ENSO precursor is not the sole forcing source that contributes to extreme winter climate in North America; rather, it is one forcing source that is increasingly influential. Previous studies [Palmer, 2014; Stevenson et al., 2012] have pointed out that, regardless of any change in the magnitude of ENSO events, the associated teleconnection would intensify due to the mean-state changes (increased mean SST), and this would strengthen the teleconnection influences on precipitation fluctuations in North America. Although the climate variations in California and the U.S. Midwest are controlled not only by the dipole but also by other climate modes (like mature-phase ENSO and PDO), the dynamical pathway between the dipole and the changing ENSO precursor as identified here could assist in monitoring such events in the future.

\section{Acknowledgements}

This research was supported by grants NNX13AC37G and WaterSMART R13AC80039, and the Utah Agricultural Experiment Station. Jin-Ho Yoon was supported by the Office of Science of the U.S. Department of Energy (DOE) as part of the Earth System Modeling program. 


\section{References}

Annamalai, H., H. Okajima, and M. Watanabe (2007), Possible impact of the Indian Ocean SST on the Northern Hemisphere circulation during El Niño*, J. Climate, 20(13), 3164-3189. Barsugli, J. J., and P. D. Sardeshmukh (2002), Global atmospheric sensitivity to tropical SST anomalies throughout the Indo-Pacific basin, J. Climate, 15(23), 3427-3442.

Branstator, G. (1983), Horizontal Energy propagation in a Barotropic Atmosphere with Meridional and Zonal Structure, J. Atmos. Sci., 40(7), 1689-1708.

Branstator, G. (1985), Analysis of General Circulation Model Sea-Surface Temperature Anomaly Simulations Using a Linear Model. Part I: Forced Solutions, J. Atmos. Sci., 42(21), 2225-2241.

Chang, F.-C., and J. M. Wallace (1987), Meteorological Conditions during Heat Waves and Droughts in the United States Great Plains, Mon. Wea. Rev., 115(7), 1253-1269. Collins, M., et al. (2010), The impact of global warming on the tropical Pacific Ocean and El Nino, Nature Geosci, 3(6), 391-397.

Farrara, J. D., C. R. Mechoso, and A. W. Robertson (2000), Ensembles of AGCM two-tier predictions and simulations of the circulation anomalies during winter 1997-98, Mon. Wea. Rev., 128(10), 3589-3604.

Francis, J. A., and S. J. Vavrus (2012), Evidence linking Arctic amplification to extreme weather in mid-latitudes, Geophy. Res. Lett., 39(6), L06801.

Hurrell, J. W., et al. (2013), The Community Earth System Model: A Framework for Collaborative Research, Bull. Amer. Meteor. Soc., 94(9), 1339-1360.

Kalnay, E., et al. (1996), The NCEP/NCAR 40-Year Reanalysis Project, Bull. Amer. Meteor. Soc., 77(3), 437-471.

Kaplan, A., M. Cane, Y. Kushnir, A. Clement, M. Blumenthal, and B. Rajagopalan (1998), Analyses of global sea surface temperature 1856-1991, J. Geophys. Res., 103(C9), 1856718589.

Kim, B.-M., S.-W. Son, S.-K. Min, J.-H. Jeong, S.-J. Kim, X. Zhang, T. Shim, and J.-H. Yoon (2014), Weakening of the stratospheric polar vortex by Arctic sea-ice loss, Nat Commun, 5. Kintisch, E. (2014), Into the Maelstrom, Science, 344(6181), 250-253.

Kumar, A., and M. P. Hoerling (1998), Specification of regional sea surface temperatures in atmospheric general circulation model simulations, Journal of Geophysical Research: Atmospheres (1984-2012), 103(D8), 8901-8907.

Larson, S., and B. Kirtman (2013), The Pacific Meridional Mode as a trigger for ENSO in a high - resolution coupled model, Geophy. Res. Lett., 40(12), 3189-3194.

Palmer, T. (2014), Record-breaking winters and global climate change, Science, 344(6186), 803-804.

Screen, J. A., and I. Simmonds (2013), Exploring links between Arctic amplification and midlatitude weather, Geophy. Res. Lett., n/a-n/a.

Screen, J. A., and I. Simmonds (2014), Amplified mid-latitude planetary waves favour particular regional weather extremes, Nature Clim. Change, advance online publication. Serreze, M. C., and J. A. Francis (2006), The Arctic amplification debate, Climatic Change, 76(3-4), 241-264.

Spencer, H., J. M. Slingo, and M. K. Davey (2004), Seasonal predictability of ENSO teleconnections: the role of the remote ocean response, Clim. Dynamics, 22(5), 511-526. 
Stevenson, S., B. Fox-Kemper, M. Jochum, R. Neale, C. Deser, and G. Meehl (2012), Will there be a significant change to El Niño in the twenty-first century?, J. Climate, 25(6), 2129-2145.

Taylor, K. E., R. J. Stouffer, and G. A. Meehl (2011), An Overview of CMIP5 and the Experiment Design, Bull. Amer. Meteor. Soc., 93(4), 485-498.

Teng, H., G. Branstator, H. Wang, G. A. Meehl, and W. M. Washington (2013), Probability of US heat waves affected by a subseasonal planetary wave pattern, Nature Geoscience, 6(12), 1056-1061.

Wallace, J. M., and D. S. Gutzler (1981), Teleconnections in the Geopotential Height Field during the Northern Hemisphere Winter, Mon. Wea. Rev., 109(4), 784-812.

Wang, S.-Y., M. L'Heureux, and H.-H. Chia (2012), ENSO prediction one year in advance using western North Pacific sea surface temperatures, Geophys. Res. Lett., 39(5), L05702. Wang, S.-Y., M. L'Heureux, and J.-H. Yoon (2013a), Are Greenhouse Gases Changing ENSO Precursors in the Western North Pacific?, J. Climate, 26(17), 6309-6322.

Wang, S.-Y., R. E. Davies, and R. R. Gillies (2013b), Identification of extreme precipitation threat across midlatitude regions based on short-wave circulations, Journal of Geophysical Research: Atmospheres, 118(19), 2013JD020153.

Wang, S.-Y., L. Hipps, R. R. Gillies, and J.-H. Yoon (2014), Probable causes of the abnormal ridge accompanying the 2013-2014 California drought: ENSO precursor and anthropogenic warming footprint, Geophy. Res. Lett., 41(9), 2014 GL059748. 
Table 1. CMIP5 model specifics as used in this study

\begin{tabular}{|c|c|c|c|c|}
\hline Acronym & Model full name & Center/Institute, country & \begin{tabular}{|l|}
$\begin{array}{l}\text { Resolution } \\
\text { (lon.xlat.) }\end{array}$ \\
\end{tabular} & $\begin{array}{l}\text { Ensemble } \\
\text { size (max) }\end{array}$ \\
\hline BCC-CSM1 & $\begin{array}{l}\text { Beijing Climate Center, Climate System } \\
\text { Model, version } 1.1\end{array}$ & $\begin{array}{l}\text { Beijing Climate Center, Meteorological } \\
\text { Administration, China }\end{array}$ & $2.8^{\circ} \times 2.8^{\circ}$ & 1 \\
\hline BNU-ESM & $\begin{array}{l}\text { Beijing Normal University_-Earth } \\
\text { System Model }\end{array}$ & $\begin{array}{l}\text { College of Global Change and Earth } \\
\text { System Science (GCESS), China }\end{array}$ & $2.8^{\circ} \times 2.8^{\circ}$ & 1 \\
\hline CanESM2 & Canadian Earth System Model, version 2 & $\begin{array}{l}\text { Canadian Center for Climate Modeling } \\
\text { and Analysis, Canada }\end{array}$ & $2.8^{\circ} \times 2.8^{\circ}$ & 5 \\
\hline CCSM4 & $\begin{array}{l}\text { Community Climate System Model, } \\
\text { version } 4\end{array}$ & $\begin{array}{l}\text { National Center for Atmospheric } \\
\text { Research, USA }\end{array}$ & $1.25^{\circ} \times 1.0^{\circ}$ & 5 \\
\hline $\begin{array}{l}\text { CESM1 } \\
\text { (not used here) }\end{array}$ & $\begin{array}{l}\text { Community Earth System Model, } \\
\text { version 1, with Community Atmospheric } \\
\text { Model, version } 5\end{array}$ & $\begin{array}{l}\text { National Science Foundation (NSF)- } \\
\text { Department of Energy (DOE)-NCAR, } \\
\text { USA }\end{array}$ & $1.25^{\circ} \times 1.0^{\circ}$ & 2 \\
\hline CNRM-CM5 & $\begin{array}{l}\text { Centre National de Recherches } \\
\text { Météorologiques Coupled Global } \\
\text { Climate Model, version } 5\end{array}$ & $\begin{array}{l}\text { National Centre for Meteorological } \\
\text { Research, France }\end{array}$ & $1.4^{\circ} \times 1.4^{\circ}$ & 10 \\
\hline CSIRO-Mk3 & $\begin{array}{l}\text { Commonwealth Scientific and Industrial } \\
\text { Research Organisation Mark, version } \\
\text { 3.6.0 }\end{array}$ & $\begin{array}{l}\text { Commonwealth Scientific and } \\
\text { Industrial Research Organization/ } \\
\text { Queensland Climate Change Centre of } \\
\text { Excellence, AUS }\end{array}$ & $1.8^{\circ} \times 1.8^{\circ}$ & 10 \\
\hline FGOALS-g2 & $\begin{array}{l}\text { Flexible Global Ocean-Atmosphere- } \\
\text { Land System Model, grid point version } 2\end{array}$ & $\begin{array}{l}\text { LASG, Institute of Atmospheric } \\
\text { Physics, Chinese Academy of } \\
\text { Sciences, China }\end{array}$ & $2.8^{\circ} \times 1.6^{\circ}$ & 4 \\
\hline GFDL-CM3 & $\begin{array}{l}\text { Geophysical Fluid Dynamics Laboratory } \\
\text { Climate Model version } 3\end{array}$ & $\begin{array}{l}\text { NOAA Geophysical Fluid Dynamics } \\
\text { Laboratory, USA }\end{array}$ & $2.5^{\circ} \times 2.0^{\circ}$ & 5 \\
\hline GFDL-ESM2 & $\begin{array}{l}\text { Geophysical Fluid Dynamics Laboratory } \\
\text { Earth Science Model } 2 \text { with Modular } \\
\text { Ocean Model (MOM), version } 4.1 \\
\end{array}$ & $\begin{array}{l}\text { NOAA Geophysical Fluid Dynamics } \\
\text { Laboratory, USA }\end{array}$ & $2.5^{\circ} \times 2.0^{\circ}$ & 3 \\
\hline GISS-E2-H & $\begin{array}{l}\text { Goddard Institute for Space Studies } \\
\text { Atmospheric Model E, version 2, } \\
\text { coupled with the Hybrid Coordinate } \\
\text { Ocean Model (HyCOM) }\end{array}$ & $\begin{array}{l}\text { NASA Goddard Institute for Space } \\
\text { Studies, USA }\end{array}$ & $2.5^{\circ} \times 2.0^{\circ}$ & 5 \\
\hline GISS-E2-R & $\begin{array}{l}\text { Goddard Institute for Space Studies } \\
\text { Model E, version 2, coupled with Russell } \\
\text { ocean model }\end{array}$ & $\begin{array}{l}\text { NASA Goddard Institute for Space } \\
\text { Studies, USA }\end{array}$ & $2.5^{\circ} \times 2.0^{\circ}$ & 5 \\
\hline HadGEM2-ES & $\begin{array}{l}\text { Hadley Centre Global Environmental } \\
\text { Model 2, Earth System }\end{array}$ & Met Office Hadley Centre, UK & $1.8^{\circ} \times 1.25^{\circ}$ & 4 \\
\hline $\begin{array}{l}\text { IPSL-CM5A- } \\
\text { MR }\end{array}$ & $\begin{array}{l}\text { L'Institut Pierre-Simon Laplace Coupled } \\
\text { Model, version 5A, medium resolution }\end{array}$ & Institute Pierre Simon Laplace, France & $2.5^{\circ} \times 1.25^{\circ}$ & 2 \\
\hline $\begin{array}{l}\text { MIROC-ESM- } \\
\text { CHEM }\end{array}$ & $\begin{array}{l}\text { Model for Interdisciplinary Research on } \\
\text { Climate Earth System Model, chemistry } \\
\text { coupled version }\end{array}$ & $\begin{array}{l}\text { Japan Agency for Marine-Earth } \\
\text { Science and Technology, Atmosphere } \\
\text { and Ocean Research Institute (The } \\
\text { University of Tokyo), and National } \\
\text { Institute for Environmental Studies, } \\
\text { Japan }\end{array}$ & $2.8^{\circ} \times 2.8^{\circ}$ & 3 \\
\hline MIROC-ESM & $\begin{array}{l}\text { Model for Interdisciplinary Research on } \\
\text { Climate Earth System Model }\end{array}$ & $\begin{array}{l}\text { Japan Agency for Marine-Earth } \\
\text { Science and Technology, Atmosphere } \\
\text { and Ocean Research Institute (The } \\
\text { University of Tokyo), and National } \\
\text { Institute for Environmental Studies, } \\
\text { Japan }\end{array}$ & $2.8^{\circ} \times 2.8^{\circ}$ & 3 \\
\hline MRI-CGCM3 & $\begin{array}{l}\text { Meteorological Research Institute } \\
\text { Coupled General Circulation Model, } \\
\text { version } 3\end{array}$ & $\begin{array}{l}\text { Meteorological Research Institute, } \\
\text { Japan }\end{array}$ & $1.1^{\circ} \times 1.1^{\circ}$ & 3 \\
\hline NorESM1-M & $\begin{array}{l}\text { Norwegian Earth System Model, version } \\
1, \text { intermediate resolution }\end{array}$ & Norwegian Climate Center, Norway & $2.5^{\circ} \times 1.9^{\circ}$ & 3 \\
\hline
\end{tabular}




\section{Figure Captions}

Fig. 1 [Extracted from Wang et al. 2014] (a) Departure of 250-hPa geopotential height (Z250) in November 2013-January 2014 from climatology showing the dipole (contour interval 25m), and (b) regression of NDJ Z250 with Nino4(Y+1) for the period of 1960-2013. Right panels are the corresponding SST analyses. Dotted areas indicate significance at $\mathrm{p}<.05$. (c)-(e) Same as (b) but regressed with Nino3.4(Y+1) for ALL, GHG and NAT forcing experiments of CMIP5 averaged from each member of each model with an equal weight, for the period 1960-2005.

Fig. 2 Top three panels: Precipitation regressions with Nino3.4(Y+1) for the NDJ season from CMIP5 (a) ALL, (b) GHG, and (c) NAT forcing experiments; dotted areas indicate significance at $\mathrm{p}<.05$. Bottom three panels: Streamfunction responses in the barotropic model forced with (d) the western Pacific forcing, (e) tropical Atlantic forcing, and (f) combined forcings; outlined regions in (b) depict the increased precipitation/heating response which was used for prescribing the perturbation as vorticity source in (d)-(f). Contour interval is $6 \times 10^{5} \mathrm{~m}^{2} \mathrm{~s}^{-1}$ omitting zeros.

Fig. 3 Moving variance of the dipole index (see text) over a 30-year running window, plotted at the end year, for the ensemble of different experiments as indicated by the legend. Error bars indicate model spread from all members and all models. The dipole index was normalized (between -2 and 2) prior to computing the variance.

Fig. 4 (a) Sliding correlations between the dipole index and Niño3.4(Y+1) within a 30-year running window from good-skill models (solid color lines; see text and (b)), the rest of the models (dotted color lines) and ensembles from all CMIP5 models (thick black line) and good-skill models (thick red line). The ensemble spread of each model is not plotted. The legend of color code vs. model is shown in upper right. The gray boundary indicates the $95 \%$ confidence level. (b) Spatial correlation coefficients (bar) between the observed and simulated SST patterns over the Pacific 
1

2

3

4

5

6

7

8

9

10

11

12

13

14

15

16

17

18

19

20

21

22

23

24

25

26

27

28

29

30

31

32

33

34

35

36

37

38

39

40

41

42

43

44

45

46

47

48

49

50

51

52

53

54

55

56

57

58

59

60
Ocean in the winters prior to El Niño events, indicating model skills on ENSO precursor. The ALL, NAT and GHG forcing runs were used. The error bars indicate the ensemble spread. 
(b)

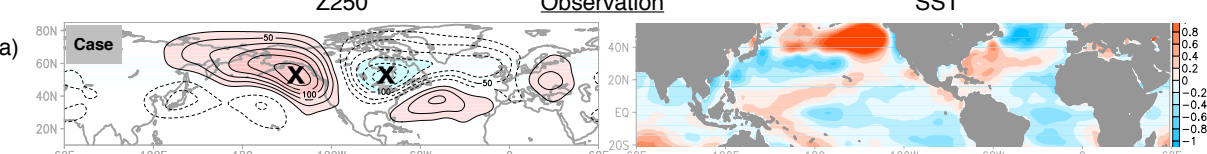

(b)

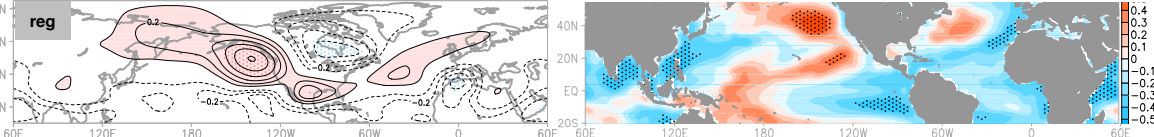

Z250

CMIP5 ensemble

SST

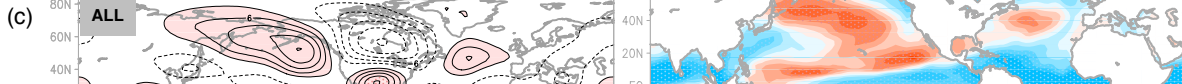

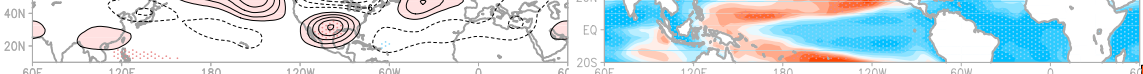

(d)

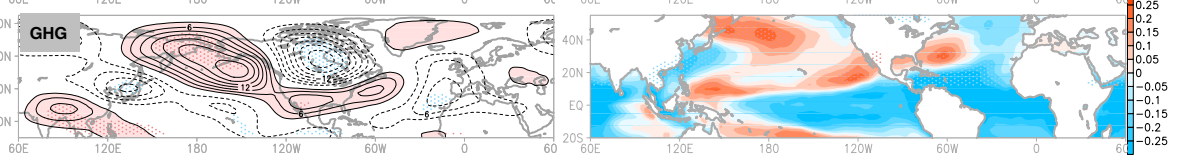

(e)

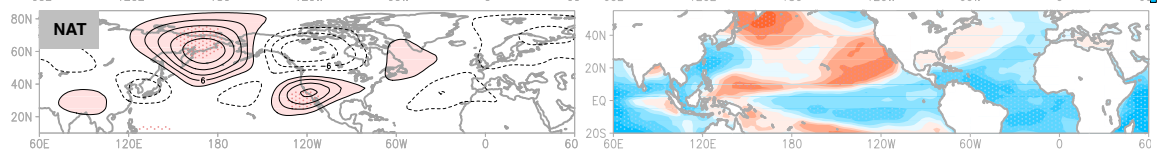

Fig. 1 [Extracted from Wang et al. 2014] (a) Departure of 250-hPa geopotential height (Z250) in November 2013January 2014 from climatology showing the dipole (contour interval 25m), and (b) regression of NDJ Z250 with Nino3.4 $(\mathrm{Y}+1)$ for the period of 1960-2013. Right panels are the corresponding SST analyses. Dotted areas indicate significance at $p<.05$. (c)-(e) Same as (b) but regressed with Nino3.4 $(Y+1)$ for ALL, GHG and NAT forcing 
(a)

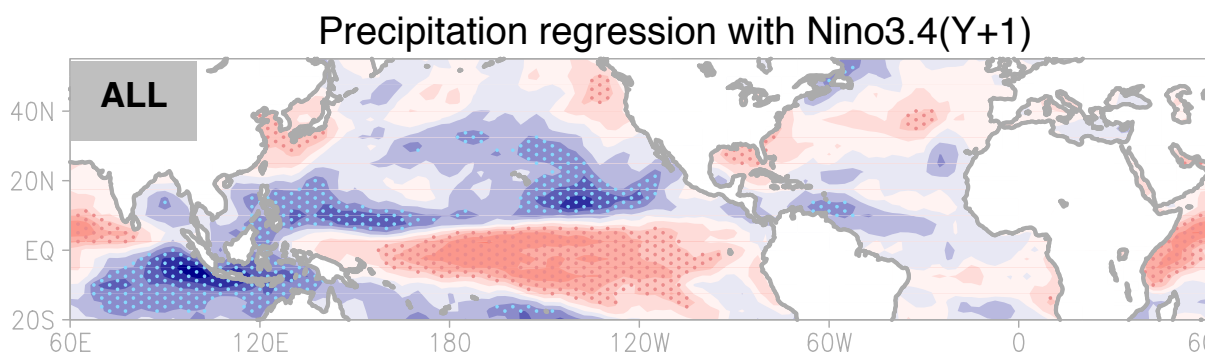

(b)

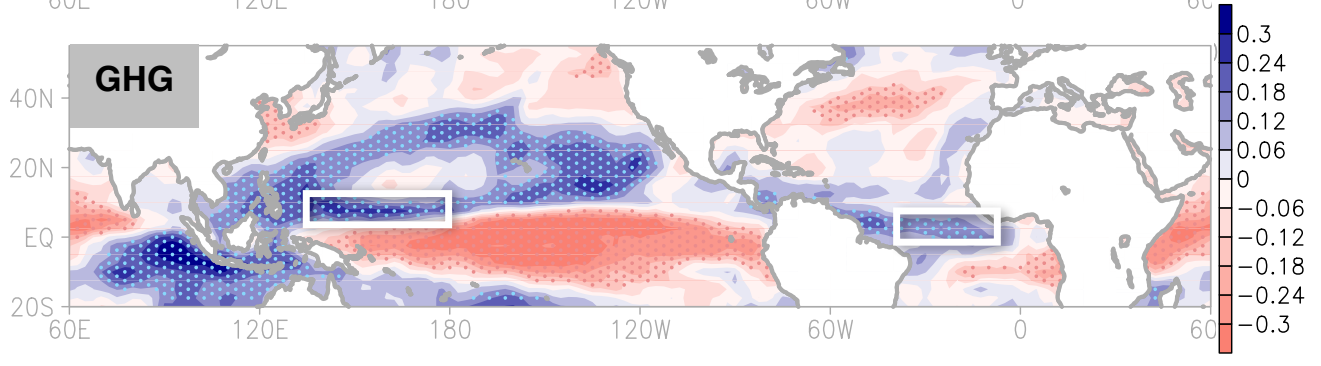

(c)

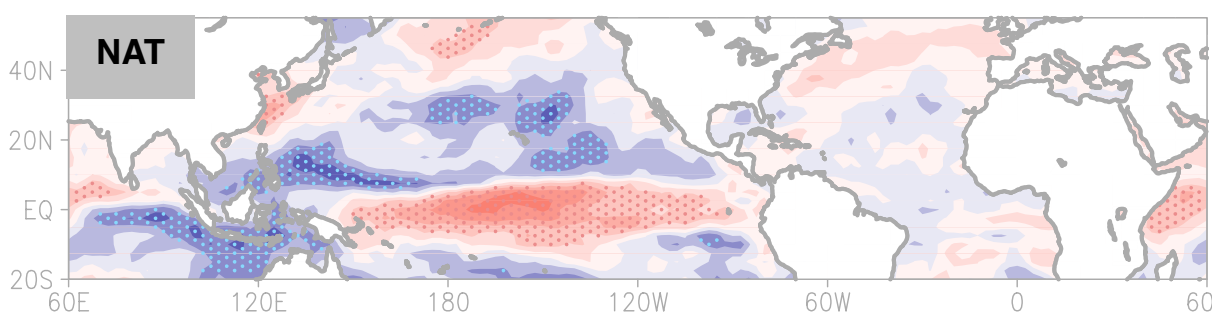

(d)

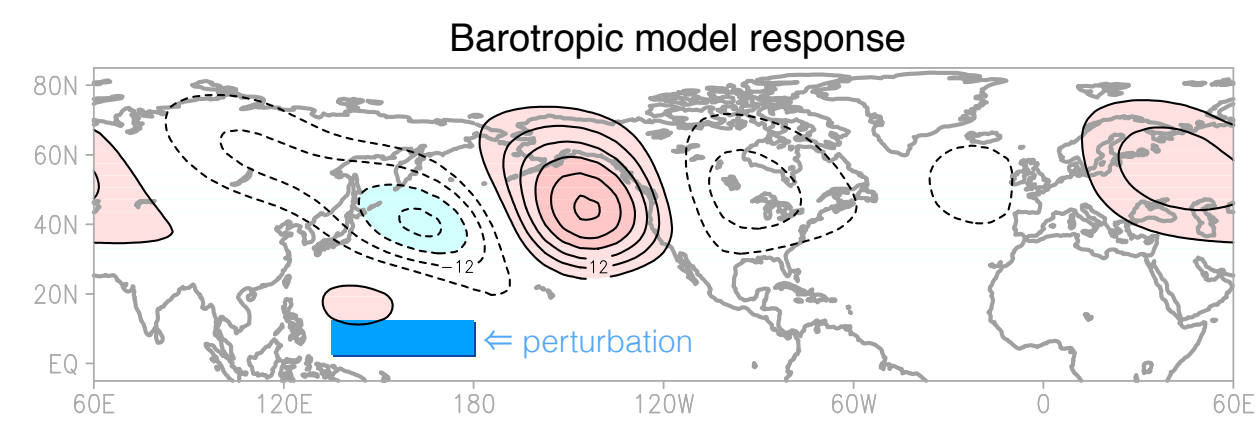

(e)

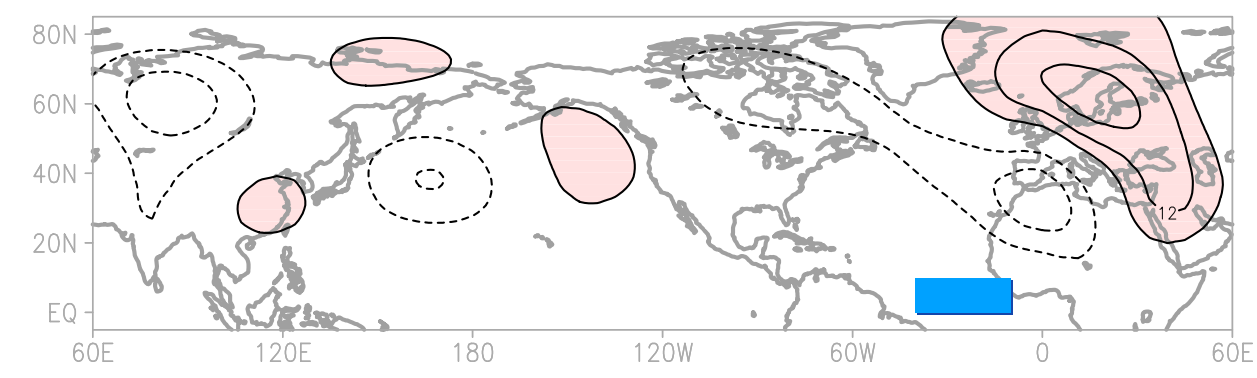

(f)

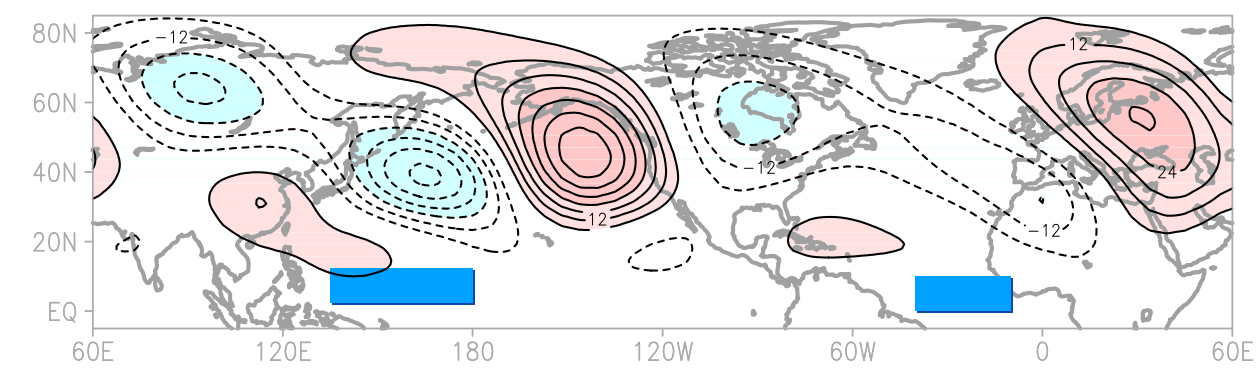

Fig. 2 Top three panels: Precipitation regressions with Nino3.4( $(Y+1)$ for the NDJ season from CMIP5 (a) ALL, (b) GHG, and (c) NAT forcing experiments; dotted areas indicate significance at $p<.05$. Bottom three panels: Streamfunction responses in the barotropic model forced with (d) the western Pacific forcing, (e) tropical Atlantic forcing, and (f) combined forcings; outlined regions in (b) depict the increased precipitation/heating response which was used for prescribing the perturbation as vorticity source in (d)-(f). Contour interval is $6 \times 10^{5} \mathrm{~m}^{2} \mathrm{~s}^{-1}$ omitting zeros. 


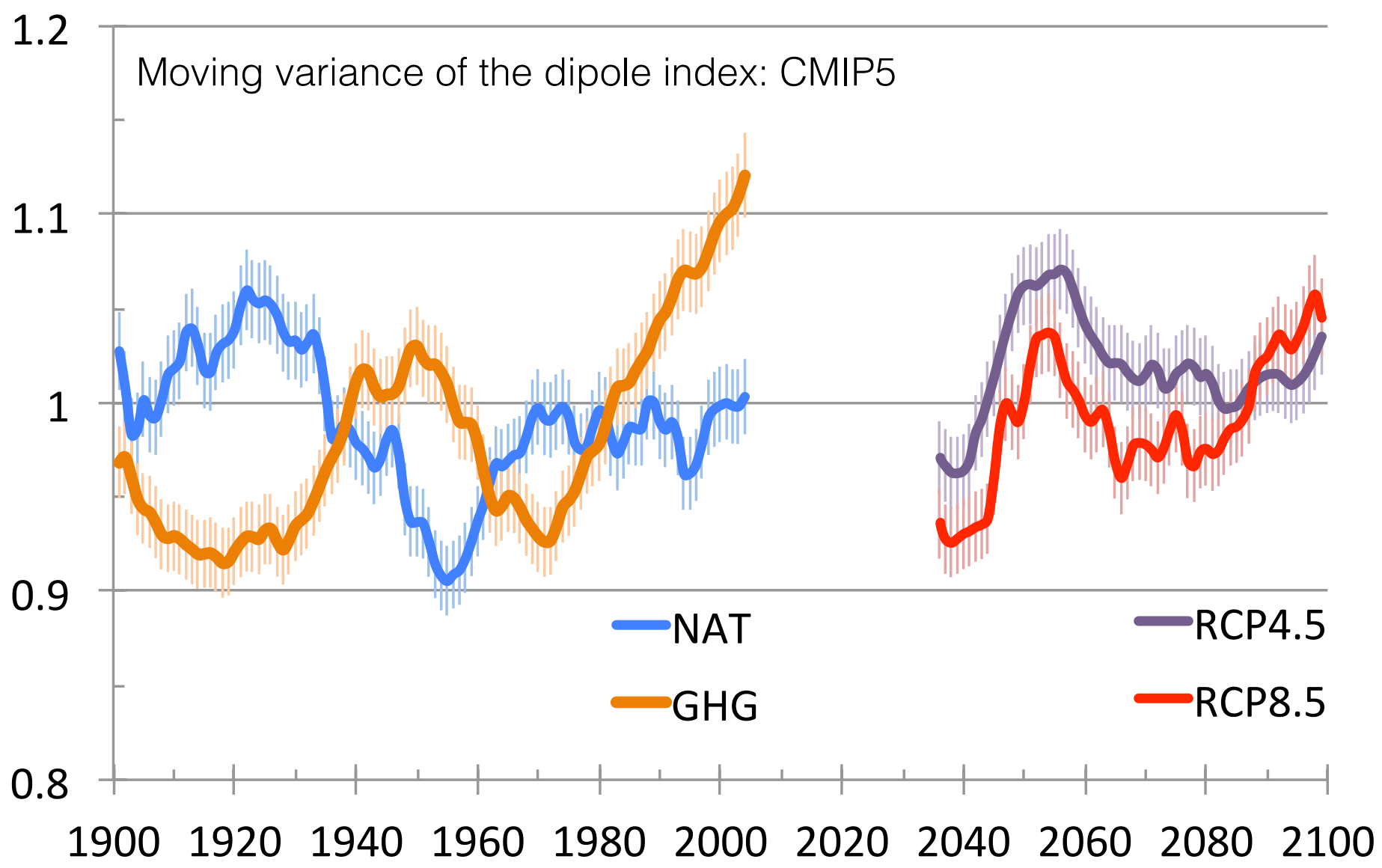

Fig. 3 Moving variance of the dipole index (see text) over a 30-year running window, plotted at the end year, for the ensemble of different experiments as indicated by the legend. Error bars indicate model spread from all members and all models. The dipole index was normalized (between -2 and 2) prior to computing the variance. 
(a) Sliding correlations: Dipole vs. Nino-3.4(Y+1)
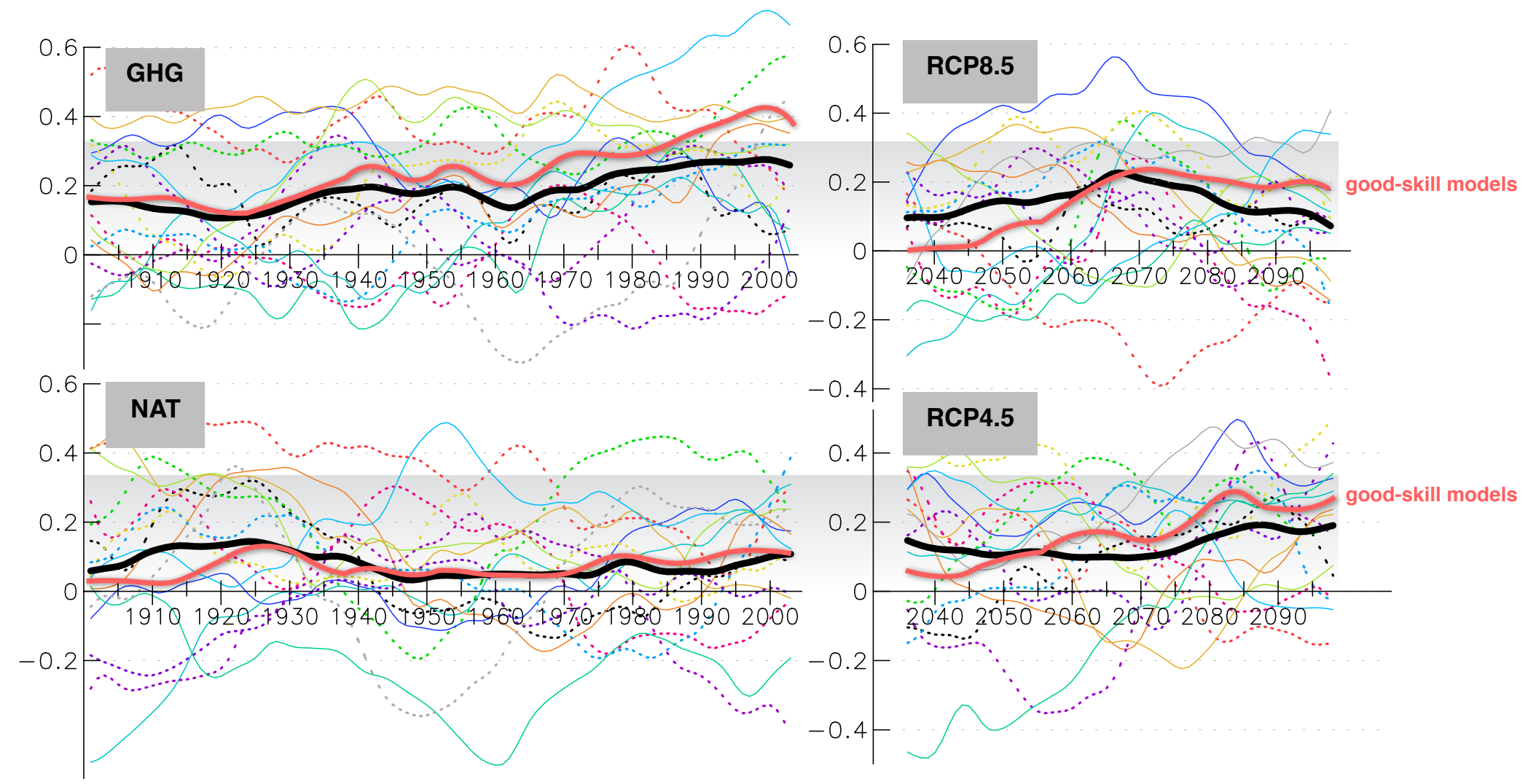

(b) Model skills on ENSO precursor
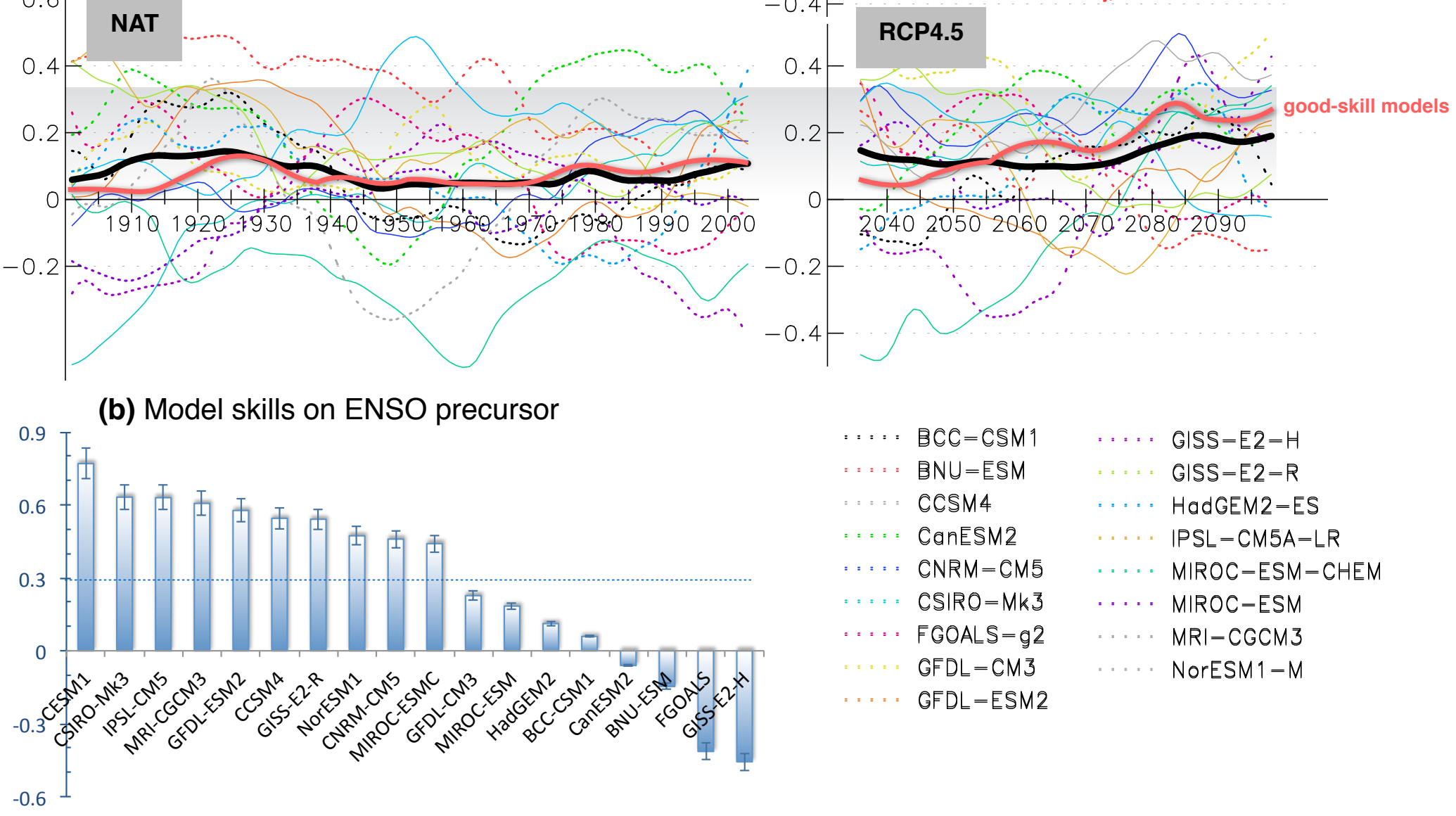

\begin{tabular}{|c|c|}
\hline$\therefore \quad$ 貝CC $=$ CSM 1 & $\therefore=\mathrm{G} \mid \mathrm{SS}=\mathrm{E} 2=\mathrm{H}$ \\
\hline BNU $=E S M$ & $\therefore=$ GISS $=E 2-R$ \\
\hline $\operatorname{ccs} 44$ & $\cdots \operatorname{HadGEM} 2=$ ES \\
\hline CanESM2 & $\therefore \quad I P S L=C M 5 A=L R$ \\
\hline$C N R M=C M 5$ & $\therefore=$ MIROC $=E S M=C H E M$ \\
\hline $\operatorname{CS} \mid R O=M k 3$ & $\cdots \cdots M I R O C=E S M$ \\
\hline$F G O A L S=g 2$ & $\therefore . . M M R I=C G C M 3$ \\
\hline $\mathrm{GFDL}=\mathrm{CM} 3$ & $\cdots$ NorESM $1=M$ \\
\hline GFDL $=$ ESM & \\
\hline
\end{tabular}

Fig. 4 (a) Sliding correlations between the dipole index and Niño3.4(Y+1) within a 30-year running window from good-skill models (solid color lines; see text and (b)), the rest of the models (dotted color lines) and ensembles from all CMIP5 models (thick black line) and good-skill models (thick red line). The ensemble spread of each model is not plotted. The legend of color code vs. model is shown in upper right. The gray boundary indicates the $95 \%$ confidence level. (b) Spatial correlation coefficients (bar) between the observed and simulated SST patterns over the Pacific Ocean in the winters prior to El Niño events, indicating model skills on ENSO precursor. The ALL, NAT and GHG forcing runs were used. The error bars indicate the ensemble spread. 